\title{
Surface Photografting of Novel Sulfobetaine Copolymers on Silica
}

\author{
Abhishek Kumar, Nazia Tarannum, Meenakshi Singh* \\ Department of Chemistry, MMV, Banaras Hindu University, Varanasi, India. \\ Email: *meenakshi_s4@rediffmail.com \\ Received March 21 $1^{\text {st }}, 2012$; revised May $1^{\text {st }}, 2012$; accepted June $1^{\text {st }}, 2012$
}

\begin{abstract}
A couple of novel sulfobetaine copolymer is developed via Michael-type addition reaction. The comonomers, diamines and maleimide react via Michael reaction through UV irradiation using AIBN as photoinitiator producing polyamine chain. Further, sulfobetaine copolymers were obtained on treatment of the polyamine with sulfopropylating agent, 1,3propane sultone. These novel sulfobetaine polymers were grafted on silica surface to produce responsive biocompatible surface. This easy straightforward, catalyst free facile protocol for synthesis of polymer grafted surface is useful for developing biomedical devices. Additionally, both the copolymers show fluorescence characteristics.
\end{abstract}

Keywords: Copolymer, Sulfobetaine; Zwitterionic; Grafted Copolymer; Photopolymerization; Maleimide; Michael-Type Reaction; Surface Initiated Polymerization (SIP); Density Functional Theory (DFT); Fluorescence

\section{Introduction}

Surface characteristics of materials involved in wide variety of commercial applications are modified by various laboratory skills, for instance physical deposition of surface-active compounds [1] or by using various "graftingto" techniques [2], through plasma or glow discharge [36], corona discharge [7-9], and $\gamma$-ray[10-12] "graftingfrom" techniques. Physical deposition by and large results in noncovalently bound coatings. Developments in UV-induced surface graft polymerization was reviewed by Deng et al. and concluded that surface graft polymerizations induced by UV irradiation exhibit some advantages over other modification methods, e.g., fast reaction rate, low cost of processing, simple equipment, easy industrialization, and may be the most important, the distribution of grafted chains is limited to a shallow region near the surface [13]. Surface photografting polymerization was also found to offer the unique ability to alter and maneuver surface properties with no damage to bulk properties. The pioneering work on photografting polymerization initiated by UV light was published in the 1950s by Oster and coworkers [14]. In view of the significance of the technique and the rapidly extending applications, it is therefore reasonable to attempt photografting of the newly synthesized maleimide copolymers bearing zwitterionic centres on silica particles.

In this work Michael type addition, a reaction tradi-

*Corresponding author. tionally used for the chemical modification of bioactive substances e.g. conjugation of peptides with polymeric substrates, such as PEG [15,16], biofucntional hydrogels [17]; is being attempted for developing responsive, biocompatible surface for biomedical and/or other industrial applications with added advantage of zwitterionic centres by fabricating sulfobetaine polyelectrolytes. Michael addition is one of the valuable and handy strategies for development of novel polymers, in which the nucleophile adds across a carbon-carbon multiple bond and has been employed for the synthesis of linear, graft, hyperbranched, dendritic and network polymers [18]. The advantages of this reaction are numerous, its mild character and high yield in physiological conditions is one of them. Although Michael addition is generally considered the addition of enolate nucleophiles to activated olefins, a wide range of functional groups possess sufficient nucleophilicity to perform as Michael donors. Reactions involving non-enolate nucleophiles such as amines, thiols and phosphines are typically referred to as Michael-type additions. Michael acceptor possesses an electron withdrawing and resonance stabilizing activating group, which stabilizes the anionic intermediate [18]. Here, the $-\mathrm{NH}_{2}$ groups of $\mathrm{N}$-(2-aminoethyl) piperazine/phenylene diamine as nucleophile was condensed with maleimide group which behaves as Michael acceptor possessing electron withdrawing activating group. The maleimide double bond is highly electrophilic due to the two adja- 
cent electron withdrawing carbonyl groups. Copolymerization is possible with a wide range of functional groups due to the variety of chemical reactions possible through the maleimide group. Condensation of maleimide with a range of functional groups is feasible as several chemical reactions are possible through the maleimide group. This study is based on the maleimide/diamine chemistry. With maleimide, reaction occurs through the double bond of maleimide ring. DFT method was used for geometry optimization and energy calculations.

\section{Experimental Section}

\subsection{Materials}

p-Phenylene diamine and silica gel (pore size $60 \AA$, 230400 mesh) were procured from Sigma Aldrich. Maleimide, $\mathrm{N}$-(2-aminoethyl)piperazine, toluene and ethanol were purchased from Merck. Azobisisobutyronitrile (AIBN) was obtained from Otto chemie Pvt. Ltd. 1,3-Propane sultone was purchased from Fluka and 3-amino propyl triethoxysilane was procured from Lancaster Synthesis. All the chemicals were of AR grade and used as received. Water used was triple distilled deionized water $(0.05$ $0.08 \times 10^{-6} \mathrm{~S} / \mathrm{cm}$ ).

\subsection{Equipments}

Elemental analyses were carried out by Vario EL III CHNS. The infrared spectra of the materials were recorded using Jasco FTIR 5300 from $400-4000 \mathrm{~cm}^{-1}$. NMR spectra were recorded using JEOL AL300 FTNMR. A chamber fitted with mercury lamp (150W) was used for UV irradiation. A Cary 50 Bio (Varian Instrument Inc., Melbourne Australia) was used for all spectrophotometric measurements. $\mathrm{pH}$ of the solutions were determined by Systronics $\mu \mathrm{pH}$ system 361. Scanning electron microscopy was performed by FESEM Quanta 200F at 5 $\mathrm{KV}$ in low vacuum. Absorption and fluorescence spectra were recorded on JASCO UV-550 spectrophotometer and JASCO FP-777 spectrofluorometer.

\subsection{Computational Method}

All computer simulations were undertaken by the Gaussian software [19]. Geometry optimization and energy calculations were performed using DFT method at B3LYP/ $6-31 G(d, p)$ level of theory.

\subsubsection{N-[2-Ammonium Ethyl Piperazinium] Maleimidopropane Sulfonate Copolymer (I)}

\subsubsection{Synthesis}

Equimolar solutions of maleimide $[0.9712 \mathrm{~g}(0.01 \mathrm{~mol})$ in $20.0 \mathrm{~mL}$ toluene] and 2-aminoethyl piperazine [1.3118 $\mathrm{mL}(0.01 \mathrm{~mol})$ in $10.0 \mathrm{~mL}$ toluene] were prepared separately. The solutions were mixed and photopolymerized by exposure to UV light using AIBN as initiator. Once polymerized, solution of 1,3-propane sultone $[0.8774 \mathrm{~mL}$ $(0.01 \mathrm{~mol})$ in $5.0 \mathrm{~mL}$ toluene] was added to the reaction mixture and continued the reaction process under UV light. Yellow fine crystals were obtained on completion of the reaction and were washed in copious amounts of toluene to remove any unreacted species and dried in oven, $\mathrm{mp} 180^{\circ} \mathrm{C}$. The product (yield $70 \%$ ) was washed several times with water also and then dried in vacuo at room temperature. Analysis (\%): $\mathrm{C}=41.8, \mathrm{H}=6.3, \mathrm{~N}=$ 12.4. The indicated structure confirms the theoretical percentages $(\mathrm{C}=41.0, \mathrm{H}=6.0, \mathrm{~N}=11.9)$; where molecular weight of a monomer is $468 \mathrm{~g} / \mathrm{mol}$ with the formula $\mathrm{C}_{16} \mathrm{H}_{28} \mathrm{~N}_{4} \mathrm{O}_{8} \mathrm{~S}_{2}$ including end group. The corresponding structure is shown in Scheme 1.

\subsubsection{Characterization}

\section{FTIR (400 - $\left.4000 \mathrm{~cm}^{-1}, \mathrm{KBr}\right)$ :}

3446 ( $v-\mathrm{NH}), 2944$ (asym v-CH ${ }_{2}$ ), 2833 (sym v- $\mathrm{CH}_{2}$ ), $1713(v-\mathrm{C}=\mathrm{O}), \quad 1461$ (scissoring $\left.v-\mathrm{CH}_{2}\right), 1179,1039$ (asym, sym $v-\mathrm{SO}_{3}^{-}$), 792 ( $\left.v-\mathrm{C}-\mathrm{H}\right), 732$ ( $v-\mathrm{NH}$ wagging).

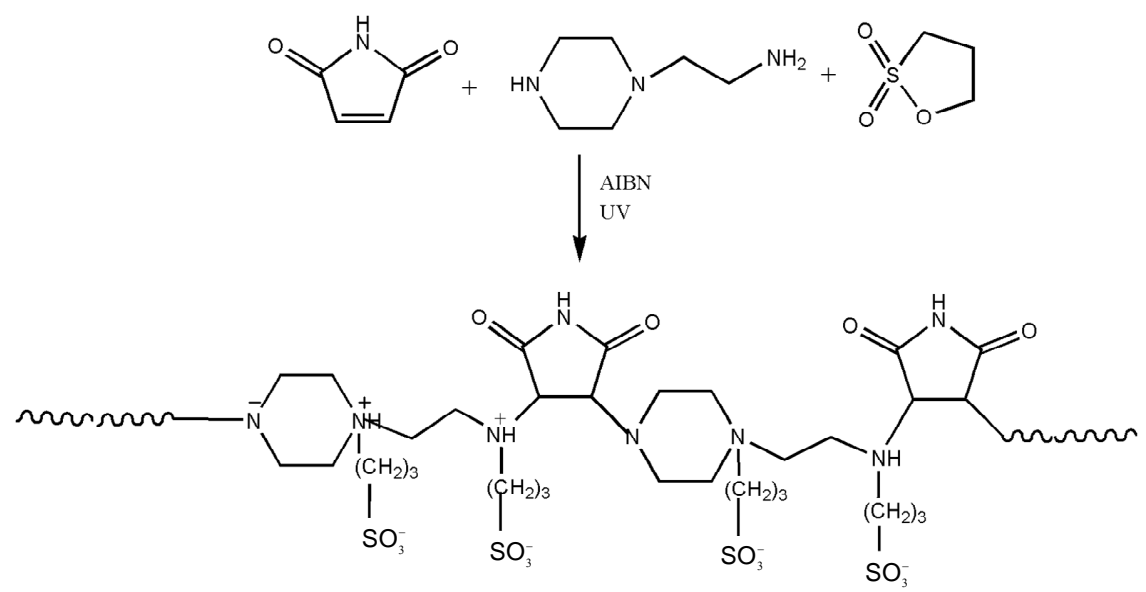

Scheme 1. Scheme of the polycondensation reaction for the polymer I. 
$\mathrm{H}^{1} \mathrm{NMR}\left(300 \mathrm{MHz}, \mathrm{CDCl}_{3}, \mathrm{ppm}\right)$ :

$\delta 8.11(1 \mathrm{H}, \mathrm{s}, \mathrm{N}-\mathrm{H}), 7.86\left(1 \mathrm{H}, \mathrm{s}, \mathrm{N}-\mathrm{H}^{+}\right), 3.41(2 \mathrm{H}, \mathrm{t}$, $\left.-\mathrm{CH}_{2}\right), 3.37\left(2 \mathrm{H}, \mathrm{t},-\mathrm{CH}_{2}-\mathrm{N}\right), 2.92(1 \mathrm{H}, \mathrm{d},-\mathrm{CH} \mathrm{C}=\mathrm{O})$, $2.58(1 \mathrm{H}, \mathrm{d})$, maleimide ring $2.5\left(2 \mathrm{H}, \mathrm{t},\left(\mathrm{N}-\mathrm{CH}_{2}\right)\right.$ piperazine ring, $2.45(2 \mathrm{H}, \mathrm{t})$ piperazine ring, $1.76(2 \mathrm{H}, \mathrm{m}$, $\mathrm{CH}_{2}-\mathrm{CH}_{2}-\mathrm{SO}_{3}^{-}$).

$\mathrm{C}^{13} \mathrm{NMR}\left(75 \mathrm{MHz}, \mathrm{CDCl}_{3}, \mathrm{ppm}\right)$ :

$\delta 178.0(\mathrm{~s}, \mathrm{C}=\mathrm{O}), 68.9(1 \mathrm{H}, \mathrm{s}, \mathrm{CH}-\mathrm{NH}), 55.8(2 \mathrm{H}, \mathrm{t}$, $\left.\mathrm{CH}_{2}-\mathrm{NH}^{+}\right), 49\left(2 \mathrm{H}, \mathrm{t}, \mathrm{N}^{+}-\mathrm{CH}_{2}\right), 45.0\left(2 \mathrm{H}, \mathrm{CH}_{2}-\mathrm{NH}\right)$, $43.01\left(2 \mathrm{H}, \mathrm{t}, \mathrm{CH}_{2}-\mathrm{SO}_{3}^{-}\right), 28.72(1 \mathrm{H}, \mathrm{s}, \mathrm{CH}-\mathrm{CO}-\mathrm{N}-), 20.5$ $\left(2 \mathrm{H}, \mathrm{t}, \mathrm{CH}_{2}-\mathrm{CH}_{2}-\mathrm{SO}_{3}^{-}\right)$.

\subsection{2. $\mathrm{N}$-[Phenylenediammonium] Maleimidopropane Sulfonate Copolymer (II)}

\subsubsection{Synthesis}

Equimolar solutions of maleimide $[0.9707 \mathrm{~g}(0.01 \mathrm{~mol})$ in $15.0 \mathrm{~mL}$ toluene], phenylene diamine [1.0814 mL $(0.01$ mol) in $15.0 \mathrm{~mL}$ toluene] were prepared separately. The solutions were mixed and photopolymerized by exposure to UV light using AIBN as initiator. Once polymerized, solution of 1,3-propane sultone $[0.8774 \mathrm{~mL}(0.01 \mathrm{~mol})$ in $5.0 \mathrm{~mL}$ toluene] was added to the reaction mixture and continued the reaction process under UV light. Dark brown crystals were obtained on completion of the reaction and were washed in copious amounts of toluene to remove any unreacted species and dried in oven. $\mathrm{mp}$ $180^{\circ} \mathrm{C}$. The product (yield $70 \%$ ) was washed several times with water also and then dried in vacuo at room temperature. Analysis (\%): $\mathrm{C}=47.2, \mathrm{H}=6.0, \mathrm{~N}=12.1$. The indicated structure confirms the theoretical percentages $(\mathrm{C}=47.5, \mathrm{H}=4.9, \mathrm{~N}=12.8)$; where molecular weight of a monomer is $325 \mathrm{~g} / \mathrm{mol}$ with the formula $\mathrm{C}_{13} \mathrm{H}_{15} \mathrm{~N}_{3} \mathrm{O}_{5} \mathrm{~S}$ including end group. The corresponding structure is shown in Scheme 2.

\subsubsection{Characterization}

FTIR (400 - $\left.4000 \mathrm{~cm}^{-1}, \mathrm{KBr}\right)$ :

3312, $3155\left(\mathrm{~d}, 2^{\circ} \mathrm{N}-\mathrm{H}\right.$ asym, sym) 3087 Aromatic str $(v-\mathrm{CH}), 2976$ Aliphatic str $(v-\mathrm{CH}), 1712(v-\mathrm{C}=\mathrm{O}), 1511$ $2^{\circ}$ Ar amine, 1358, $1250 \mathrm{C}-\mathrm{N}$ str of $v-\mathrm{NH}, 1162(\mathrm{C}-\mathrm{N}$ linkage-2 ${ }^{\circ}$ amine), 1069 (C-N str), 836 ( $v$-CH bending), 678 ( $v$-NH wagging), 673 (deformation $v-\mathrm{CH}$ ).

$\mathrm{H}^{1} \mathrm{NMR}(300 \mathrm{MHz}$, DMSO, ppm):

$\delta 11.30(1 \mathrm{H}, \mathrm{s}, \mathrm{CONH}), 7.22\left(1 \mathrm{H}, \mathrm{s}, \mathrm{N}-\mathrm{H}^{+}\right), 6.89(4 \mathrm{H}, \mathrm{m}$, benzene protons), $4.62\left(1 \mathrm{H}, \mathrm{d},-\mathrm{CO}-\mathrm{CH}-\mathrm{NH}^{+}\right), 3.49(1 \mathrm{H}, \mathrm{s}$, $\mathrm{CH}-\mathrm{CO}-), 1.85\left(2 \mathrm{H}, \mathrm{t},-\mathrm{CH}_{2}-\mathrm{SO}_{3}^{-}\right), 1.72\left(2 \mathrm{H}, \mathrm{t},-\mathrm{CH}_{2}-\right.$ $\mathrm{NH}^{+}$.

$\mathrm{C}^{13} \mathrm{NMR}(75 \mathrm{MHz}$, DMSO, ppm):

$\delta 178.7(\mathrm{~s}, \mathrm{C}=\mathrm{O}), 148.12\left(\mathrm{~s},-\mathrm{C}_{5} \mathrm{H}_{4}\right), 128.0(1 \mathrm{H}, \mathrm{d}$, benzene ring), $113.21(1 \mathrm{H}, \mathrm{d}$, benzene ring), $52.6(1 \mathrm{H}, \mathrm{d}$, -CH-CO-), 49.1 (2H, t, $\left.\mathrm{CH}_{2}-\mathrm{SO}_{3}^{-}\right), 33.6$ (1H, d-CH-CO-).

\subsection{Modification of Silica Particles}

The grafting of polymer chains on the silica particles were carried out in two steps: 1) introduction of amine groups onto the silica surface, 2) Michael addition of (a) maleimide to amino groups onto silica surface and (b) diamines on thus grafted maleimide groups on silica surface. Further cycles of reactions (a) and (b) were repeated several times to produce polymer grafted silica particles. $2.0 \mathrm{~g}$ of silica was refluxed with $5 \%$ toluene solution of 3-aminopropyl triethoxy silane for $8 \mathrm{~h}$. After the reaction, amino-terminated silica particles were filtered on silica glass crucible G-4, washed several times with toluene and dried in oven at $120^{\circ} \mathrm{C}$ for $5 \mathrm{~h}$ before use. Thus amino-terminated silica particles were subjected to Michael addition with maleimide group in step (a) and further with diamines and 1,3-propane sultone as described above under UV irradiation.
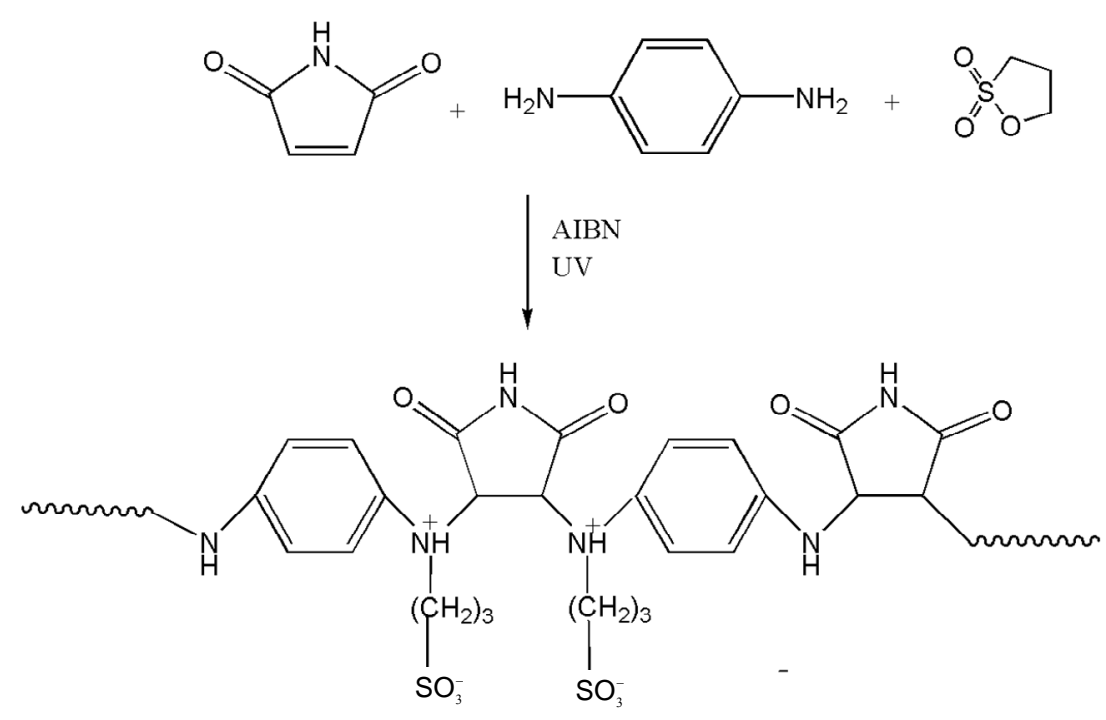

Scheme 2. Scheme of the polycondensation reaction for the polymer II. 


\subsection{Estimation of Amino Groups on Silica Surface}

Amino groups introduced on the silica surface were determined by titration. To $0.10 \mathrm{~g}$ silica particles $20 \mathrm{~mL}$ of $0.01 \mathrm{~N} \mathrm{HCl}$ was added and charged the mixture on magnetic stirrer at $65^{\circ} \mathrm{C}$ for $2 \mathrm{~h}$. The solution was filtered and filtrate was titrated with $0.01 \mathrm{~N} \mathrm{NaOH}$ using phenolphthalein as an indicator.

\subsection{Results and Discussion}

Maleimide is a 1,2-disubstituted cyclic ethylene type monomer. Maleimide group is highly reactive toward primary amine groups to perform Michael addition reactions. This group is chosen due to the facile addition of amine across the $\mathrm{e}^{-}$-deficient double bond; with maleimide, reaction occurs through the double bond of maleimide ring.

Although Michael addition is generally considered the addition of enolate nucleophiles to activated olefins, a wide range of functional groups possess sufficient nucleophilicity to perform as Michael donors [18]. Reactions involving non-enolate nucleophiles such as amines, thiols and phosphines are typically referred to as Michaeltype additions. Michael acceptor possesses an electron withdrawing and resonance stabilizing activating group, which stabilizes the anionic intermediate [18]. Here, the $-\mathrm{NH}_{2}$ groups of phenylene diamine as nucleophile was condensed with maleimide The maleimide double bond is highly electrophilic due to the two adjacent electron withdrawing carbonyl groups. Further, the polymer chain was made to react with 1,3-propane sultone, a sulfoalkylating agent. In their reaction with nucleophiles, the nitrogen centres were quaternized resulting in zwitterionic centres along the polymeric chain (Scheme 1). The sulfopropyl groups are introduced by reaction of nucleophiles with commercially available 1,3-propane sultone [20]. The sulfopropyl group has been used extensively to improve the hydrophilicity of a variety of surfactants, dyes, nucleosides, proteins and polymers [21-26].

The infrared (IR) spectra of copolymers I and II are shown in Figures $\mathbf{1}$ and 2. The imidyl group $(\mathrm{O}=\mathrm{C}-\mathrm{N}-\mathrm{C}=$ $\mathrm{O})$ in maleimide has been assigned in literature an intense peak between 1700 and $1750 \mathrm{~cm}^{-1}$ (asymmetric stretching mode) and medium/weak peaks between 1740 and $1850 \mathrm{~cm}^{-1}$ (symmetric stretching mode) [27]. The respective peaks at 1714 and 1712 could be seen in Figures 1 and $\mathbf{2}$ in the IR spectra of I and II. Absorptions for sulfonate group appear at 1342,1179 and $1039 \mathrm{~cm}^{-1}$ for I and at $1069 \mathrm{~cm}^{-1}$ in II. Other sulfonate peaks in the region around 1300 or 1150 are overlapped with $\mathrm{C}-\mathrm{N}$ stretching absorptions. But in $\mathrm{H}^{1} \mathrm{NMR}$ and $\mathrm{C}^{13} \mathrm{NMR}$ spectra, respective peaks could be observed at $7.86 \mathrm{ppm}$ and 7.22 ppm respectively. $\mathrm{H}^{1}$ NMR and $\mathrm{C}^{13}$ NMR spec- tra are shown in Figures $\mathbf{3}$ and $\mathbf{4}$.

The small peak at $128 \mathrm{ppm}$ in $\mathrm{C}^{13} \mathrm{NMR}$ of polymer I is puzzling. Generally double bonds at $\mathrm{C}$ respond in this range. Geometry optimization and energy calculations were performed using DFT method. The DFT calculation is commonly applied as it has the advantage of highly accurate level of information, reliability and reasonable computational costs in comparison with other computational methods (e.g. ab initio) [28]. Therefore, DFT

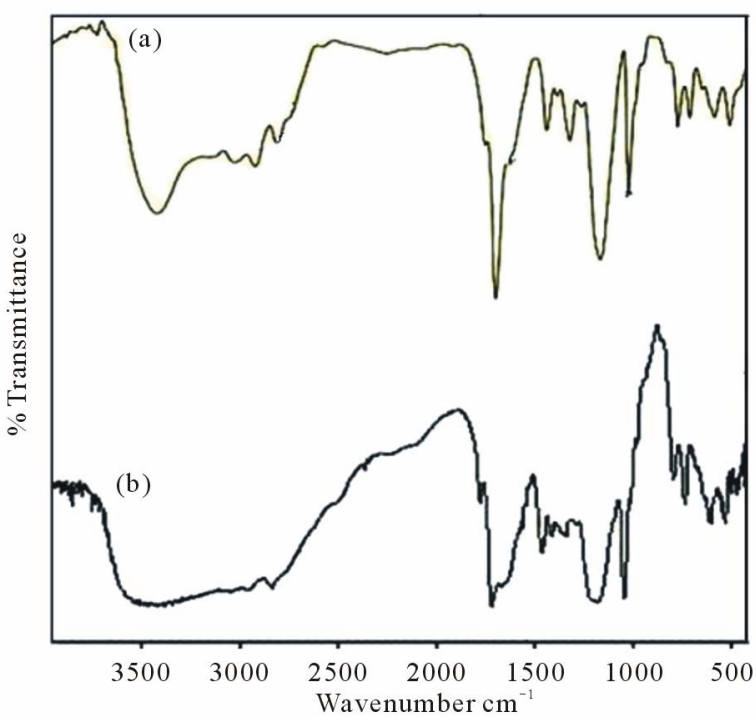

Figure 1. Infrared spectra of pure (a) and grafted polymer on silica (b) for polymer I.

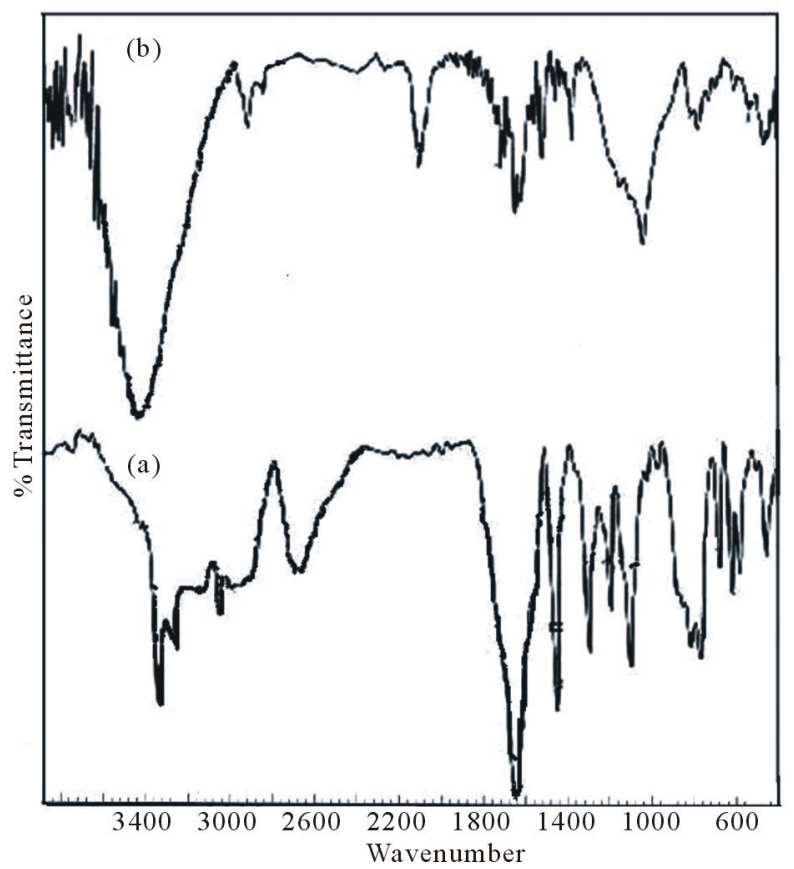

Figure 2. Infrared spectra of pure (a) and grafted polymer on silica (b) for polymer II. 


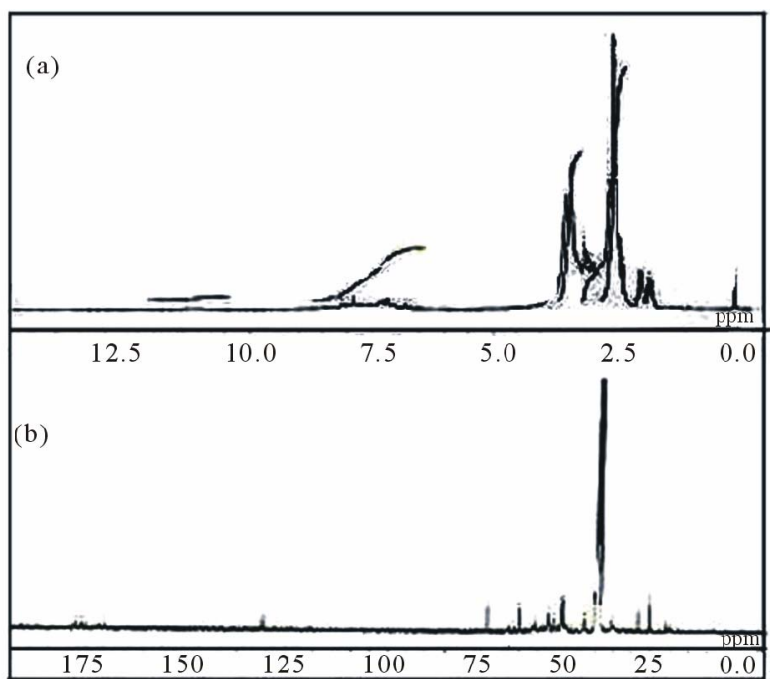

Figure 3. H $^{1}$ NMR (a) and $C^{13}$ NMR (b) spectra of polymer I.

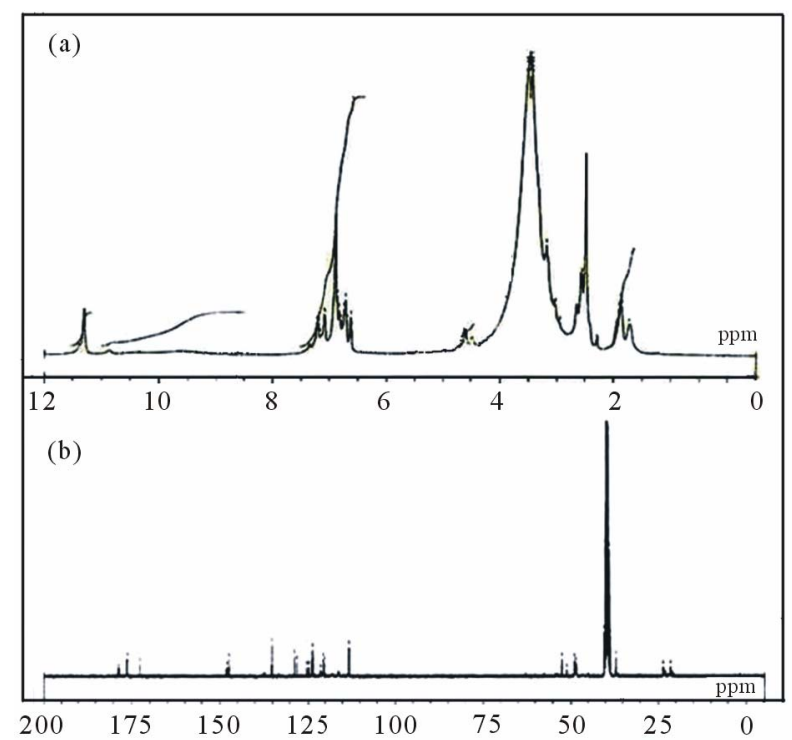

Figure 4. $\mathrm{H}^{1}$ NMR (a) and $\mathrm{C}^{13}$ NMR (b) spectra of polymer II.

method was selected to set up the calculations. The geometry optimizations were performed at B3LYP/6-31G $(d, p)$ level of theory.

The optimized structure is shown in Figures 5 and 6. This structure (Figure 5) contains one partial double bond in between $\mathrm{C} 7$ and $\mathrm{N} 6$ in the maleimide ring. The electron density of carbonyl bond and the lone pair on $\mathrm{N}$ of maleimide are supposed to involve in this partial double bond proposed by DFT calculations and evinced by $\mathrm{C}^{13}$ NMR spectra. Mü̈lliken atomic charges on the monomers and the copolymer units are provided in the supplementary material. For sake of brevity, only those atoms which have significance in our discussion are shown in the tables. In the monomer unit of copolymer I, C2 of maleimide is forming a new bond with primary amine $\mathrm{N}$

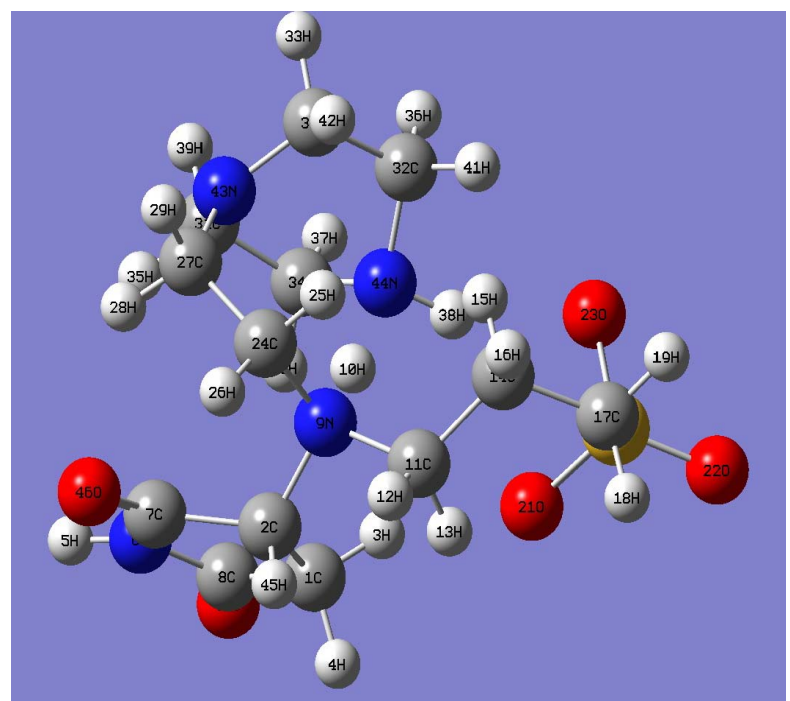

Figure 5. Optimized structures of polymer I.

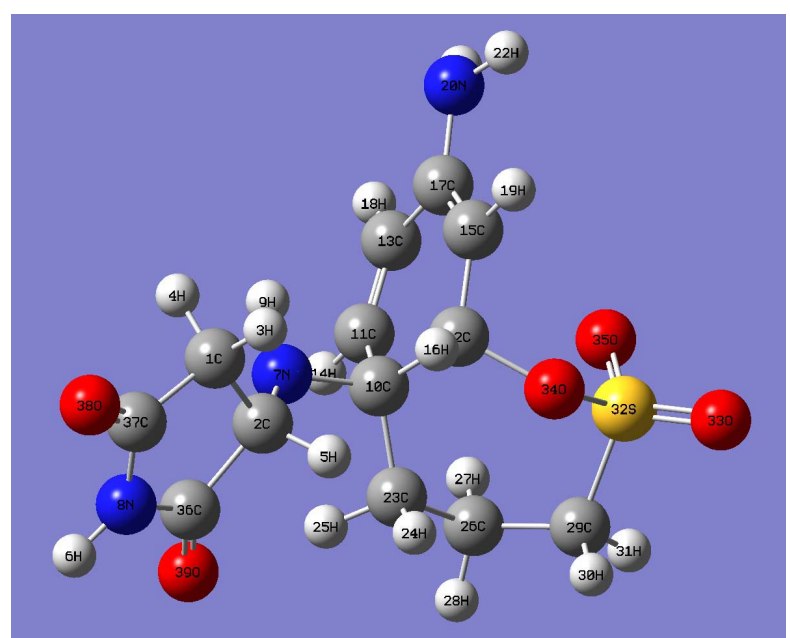

Figure 6. Optimized structures of polymer II.

of 2-aminoethyl piperazine, charge density of $\mathrm{C} 2$ has changed from $(-0.120)$ to $(+0.049)$ and that of $\mathrm{N} 9$ from $(-0.698)$ to $(+0.1537)$. The charge on $\mathrm{N}$ of maleimide ring changes from $(-0.681)$ to $(-0.0844)$. Similarly in the monomer unit of copolymer II, charge density of C2 has changed from $(-0.120)$ to $(+0.039)$ and that of $\mathrm{N} 7$ from $(-0.836)$ to $(-0.1487)$. The charge on $\mathrm{N}$ of maleimide ring changes from $(-0.681)$ to $(-0.0952)$. The computed dipole moment of I is 19.76 debye whereas that of II is 2.76 (Table 1). The copolymer I is highly polar. In the end, the partial double bond in maleimide ring proposed by the DFT computations might be assigned to the 128 ppm peak in $\mathrm{C}^{13}$ NMR spectra as shown in Figure 5.

Table 2 shows the solubility of polymers in various solvents. Polymers are insoluble in water but they are soluble in various solvents including dipolar aprotic solvents.

UV and Fluorescence spectra of polymers are shown 
Table 1. Energies and dipole moments of monomer constituents and monomers.

\begin{tabular}{c|ccc|}
\hline S. No. & Compounds & Energy (Hartree) in gas phase DFT B3LYP/6-31G(2d,p) (au) & Dipole moment (debye) \\
\hline 1. & Maleimide & -359.17 & 3.62 \\
2. & N-(2-aminoethyl)piperazine & -401.64 & 1.58 \\
3. & P-phenylene diamine & -341.04 & 1.50 \\
4. & 1,3 propane sultone & -741.57 & 9.45 \\
5. & Monomer I & -1501.55 & 19.76 \\
6. & Monomer II & -1443.16 & 2.76 \\
\hline
\end{tabular}

Table 2. Solubility of polymers in various solvents.

\begin{tabular}{ccc}
\hline Solvent & I & II \\
\hline DMF & $\sqrt{ }$ & $\sqrt{ }$ \\
Ethanol & $\sqrt{ }$ & $\times$ \\
Toluene & $\sqrt{ }$ & $\times$ \\
Acetone & $\#$ & $\sqrt{ }$ \\
DMSO & $\sqrt{ }$ \\
Acetonitrile & $\sqrt{ }$ & $\times$ \\
Tetrahydro furan & $\#$ & $\sqrt{ }$ \\
\hline
\end{tabular}

$\sqrt{ }$ —-soluble; $\times$-Insoluble; \#-soluble on heating.

in Figures 7. Absorption and fluorescence spectra of polymer I and II were recorded in the solution of ethanol:water $(1: 1)$ at concentration of $0.0024 \mathrm{~g} / \mathrm{L}$ and 0.0012 $\mathrm{g} / \mathrm{L}$, respectively. Absorption spectra of polymers show absorption at $253 \mathrm{~nm}$. Further, on exciting the polymers I and II at $256 \mathrm{~nm}$ and $250 \mathrm{~nm}$, respectively, strong emission band was obtained for both at $357.5 \mathrm{~nm}$. The fluorescence behaviour of the polymers can be attributed to chromophoric group maleimide.

The purpose of this study is to prepare a "responsive" polymer grafted surface for various purposes as required in different biomedical and/or industrial applications. To overcome the limitations of physically deposited polymers on the surface, the "grafted from" procedure was adopted to implant newly synthesized polymer on silica surface. Amine groups introduced on the silica surface (Schemes 3 and 4) were made to react with maleimide under UV irradiation using AIBN as initiator. Thus attached maleimide groups were subsequently reacted with diamines and maleimide and so on in stepwise reactions as in the bulk polymerization discussed above. The copolymer chain was thus grown up from amine grafted silica particles. The IR spectra of copolymer and the silica grafted copolymer are shown in Figures $\mathbf{1}$ and 2. NMR spectra of grafted silica particles could not be recorded due to solubility problem.

A strong Si-O-Si absorption at $1110 \mathrm{~cm}^{-1}$ as well as

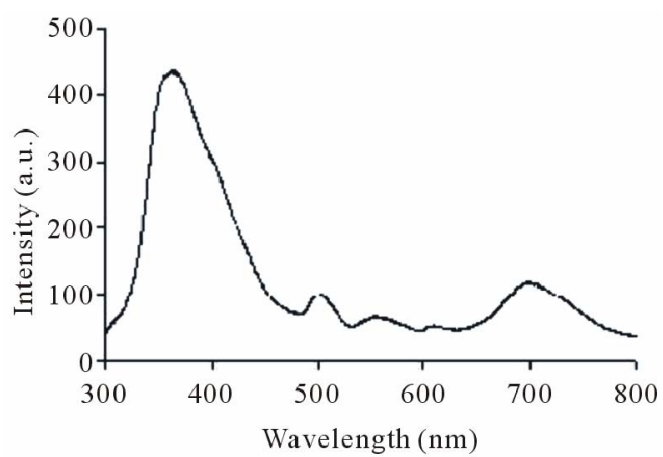

(a)

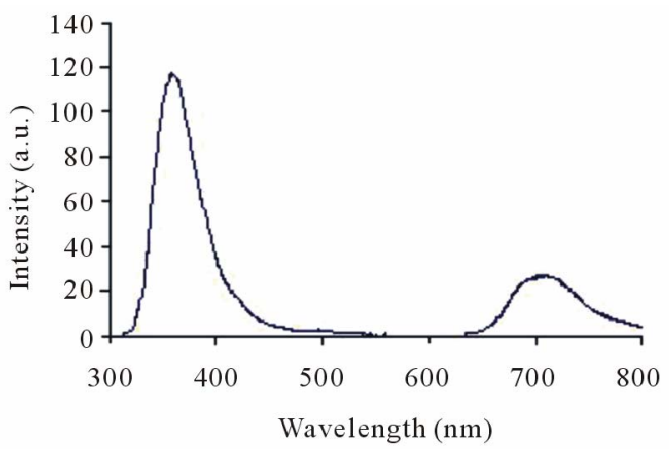

(b)

Figure 7. Fluorescence spectra of polymer I (a) and II (b).

1715, 1680 absorptions other characteristic absorptions as observed in the spectra of bulk polymer appeared in the FTIR spectrum of polymer grafted silica (Figures 1 and 2), indicating that copolymer units were successfully incorporated onto the silica particles. The Michael addition reaction between the amine and maleimide groups formed succinimide groups, which should represent an absorption peak at about $1180 \mathrm{~cm}^{-1}$ which has been overlapped with the silica and sulfonate group absorptions. The content of amino group charged on the surface of silica as an initiator site as per the titration is 0.027 $\mathrm{mmol} / \mathrm{g}$ whereas the grafting of polyelectrolyte on silica surface leaves behind $6.70 \times 10^{-3} \mathrm{mmol} / \mathrm{g}$ of amino centres in case of copolymer I and $2.9 \times 10^{-3}$ on grafting of copolymer II. 

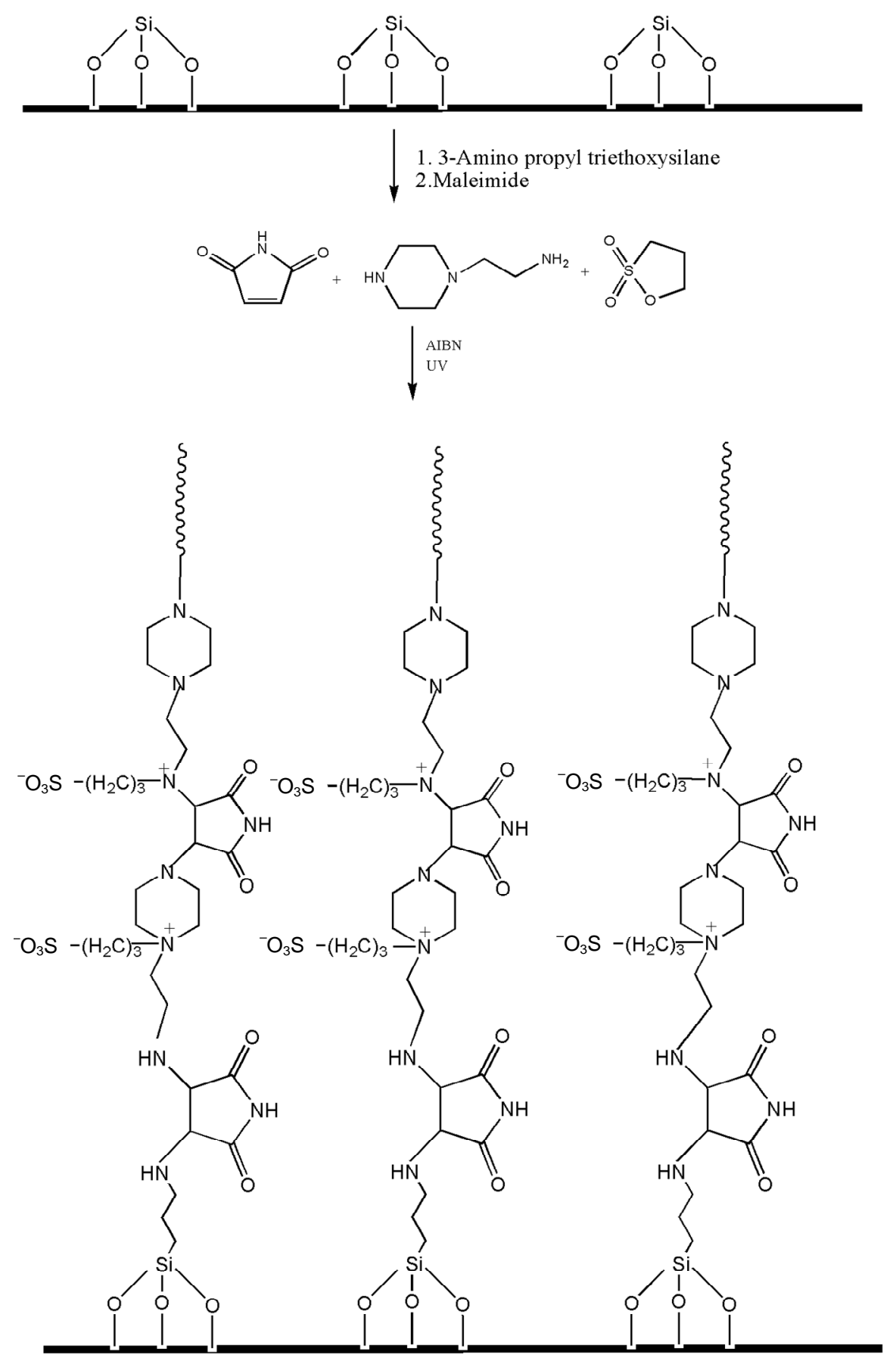

Scheme 3. Grafting of polymer I on silica particles.

The images of bulk polymer and polymer grafted silica particles from scanning electron microscopy technique are shown in Figures 8 and 9. Successful grafting of polymers could be noticed in the images. The grafted surface shows more coarseness than pure silica particle surface.

Further, the grafted surface thus developed has shown good prospects in our laboratory's experiments as imprinted material to develop the sensitive and highly selective analytical technique to analyze small peptides with complementary chemistry.

\section{Conclusion}

In summary, we have presented a synthetic protocol for the design and build up of responsive polymer grafted surface based on Michael reaction, a versatile tool in polymer synthesis. At first, a pair of new sulfobetaine polymer is synthesized using Michael addition through 

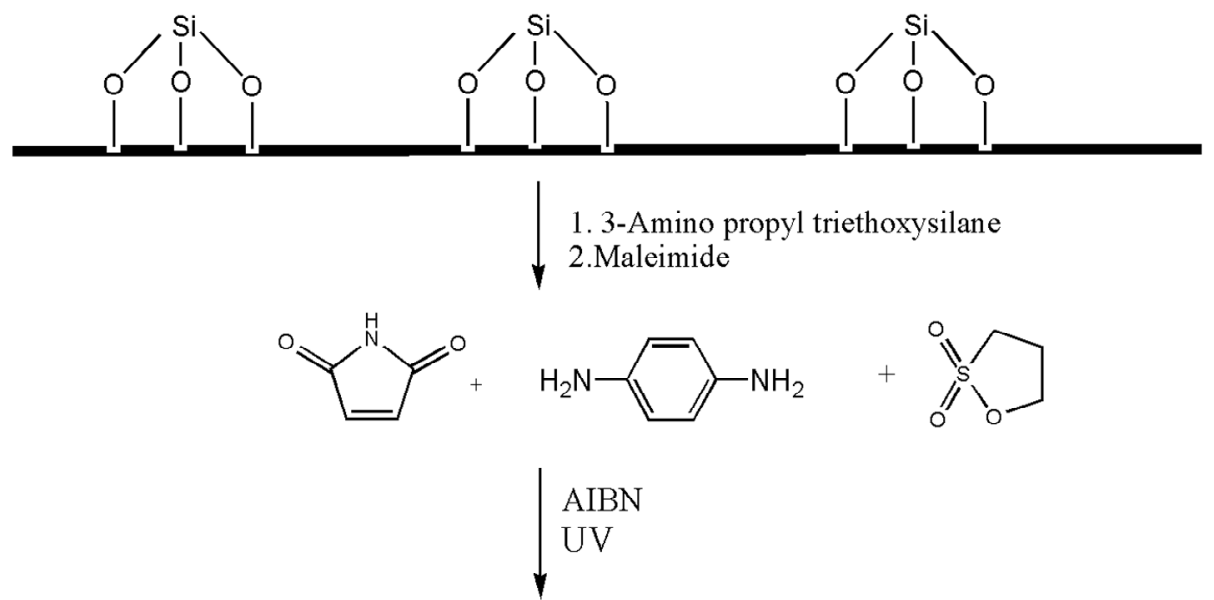
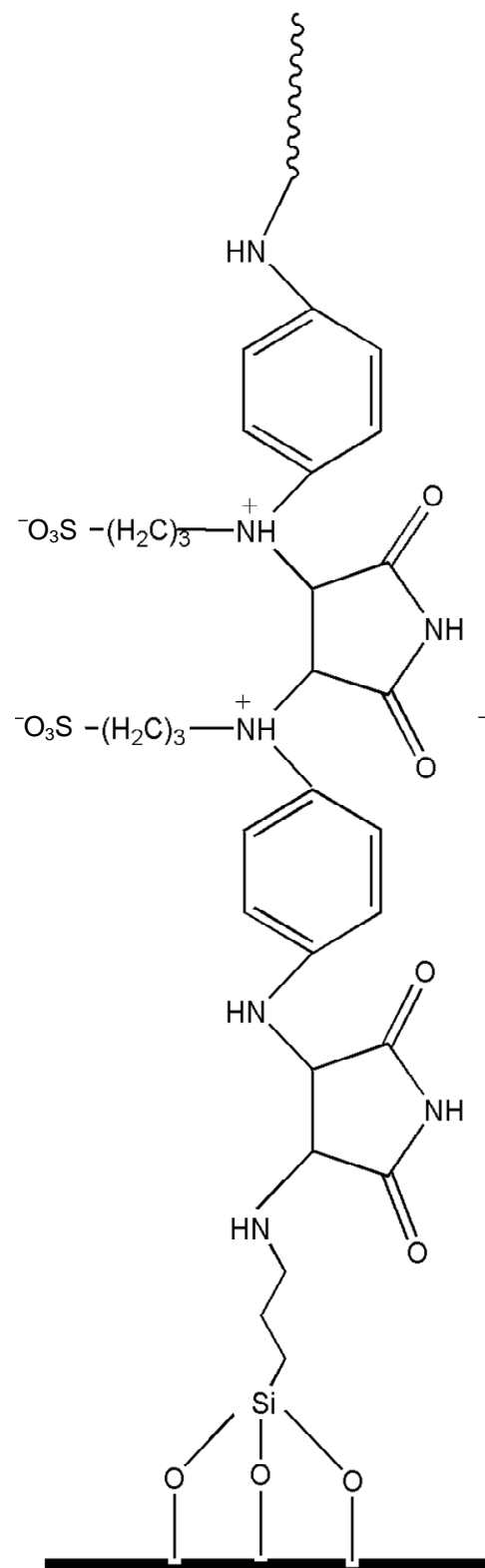
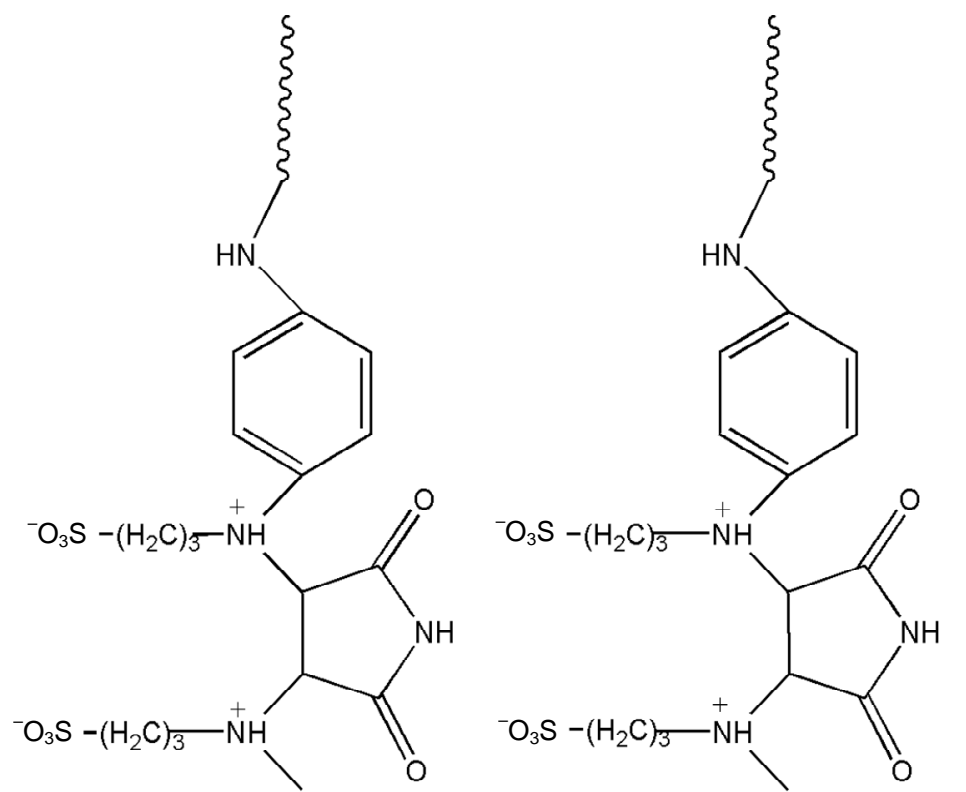

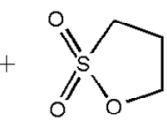
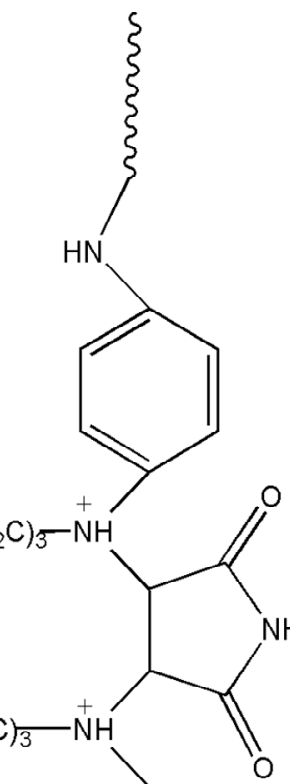<smiles>c1ccccc1</smiles><smiles>CCNC1C(=O)NC(=O)C1NC</smiles><smiles>c1ccccc1</smiles><smiles>CNC1C(=O)NC(=O)C1NC</smiles>

Scheme 4. Grafting of polymer II on silica particles. 


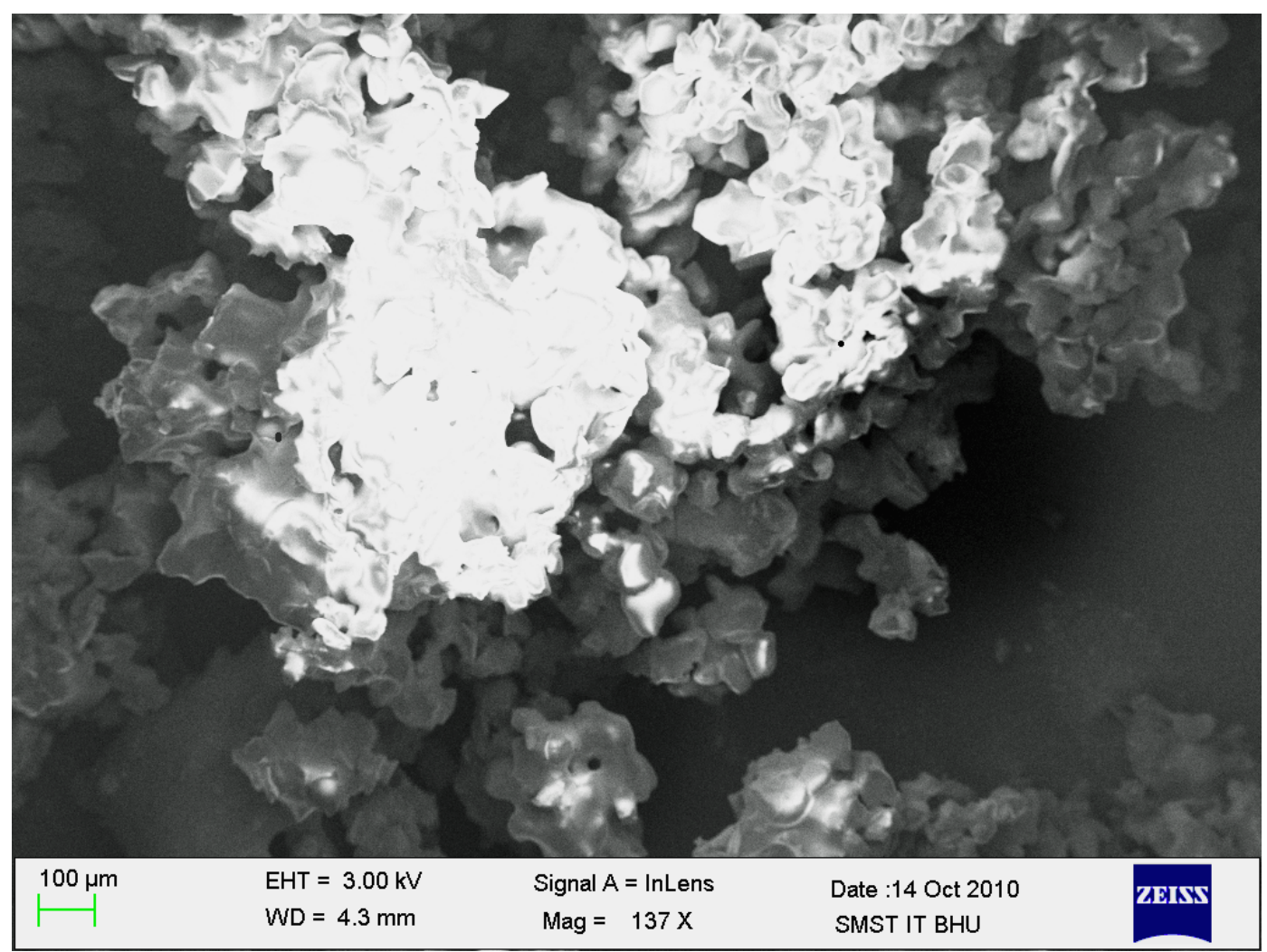

(a)

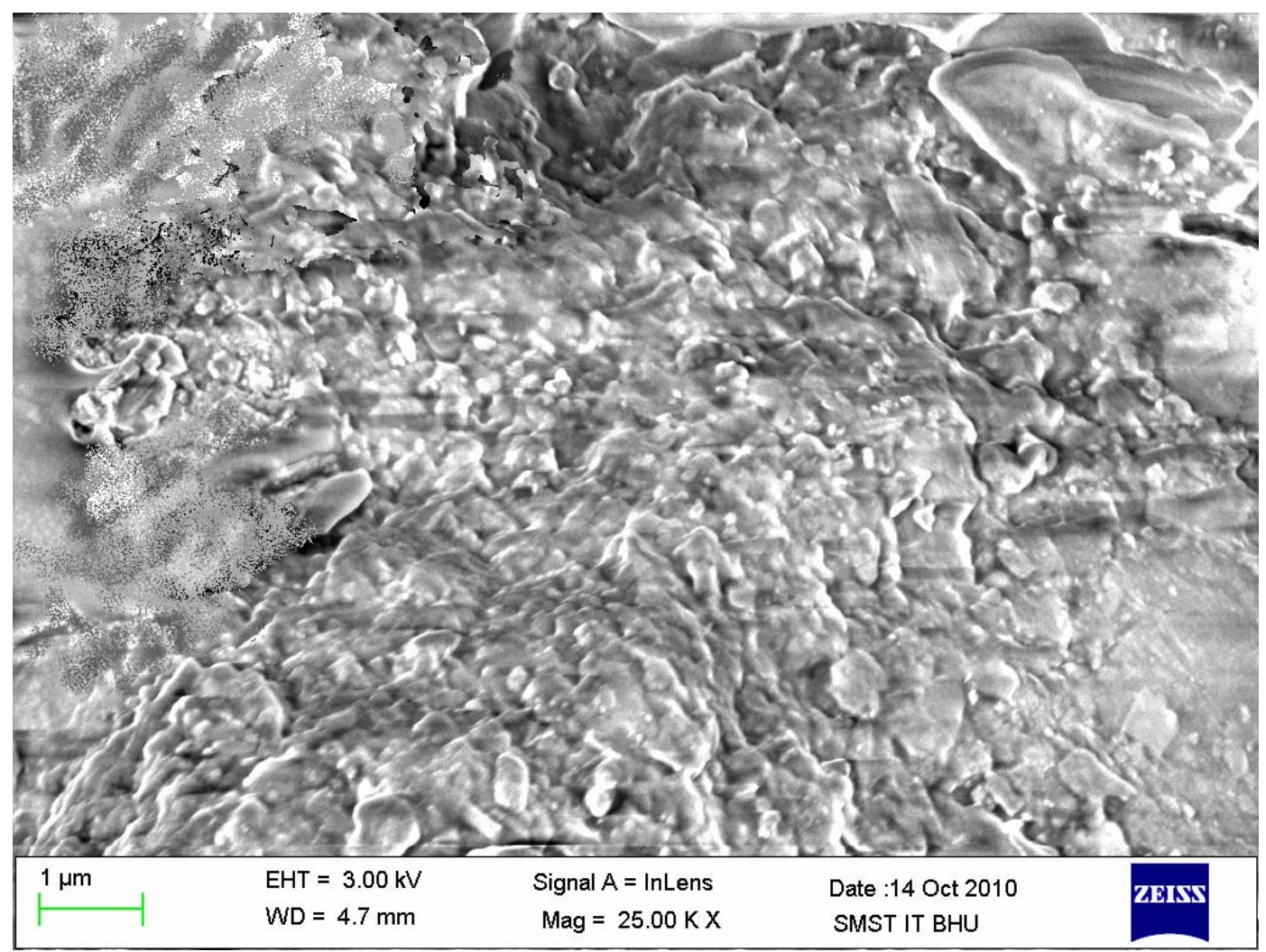

(b)

Figure 8. Scanning electron microscopy of grafted polymer I on silica (a) at $137 \times$ and (b) at $25000 \times$ magnification. 


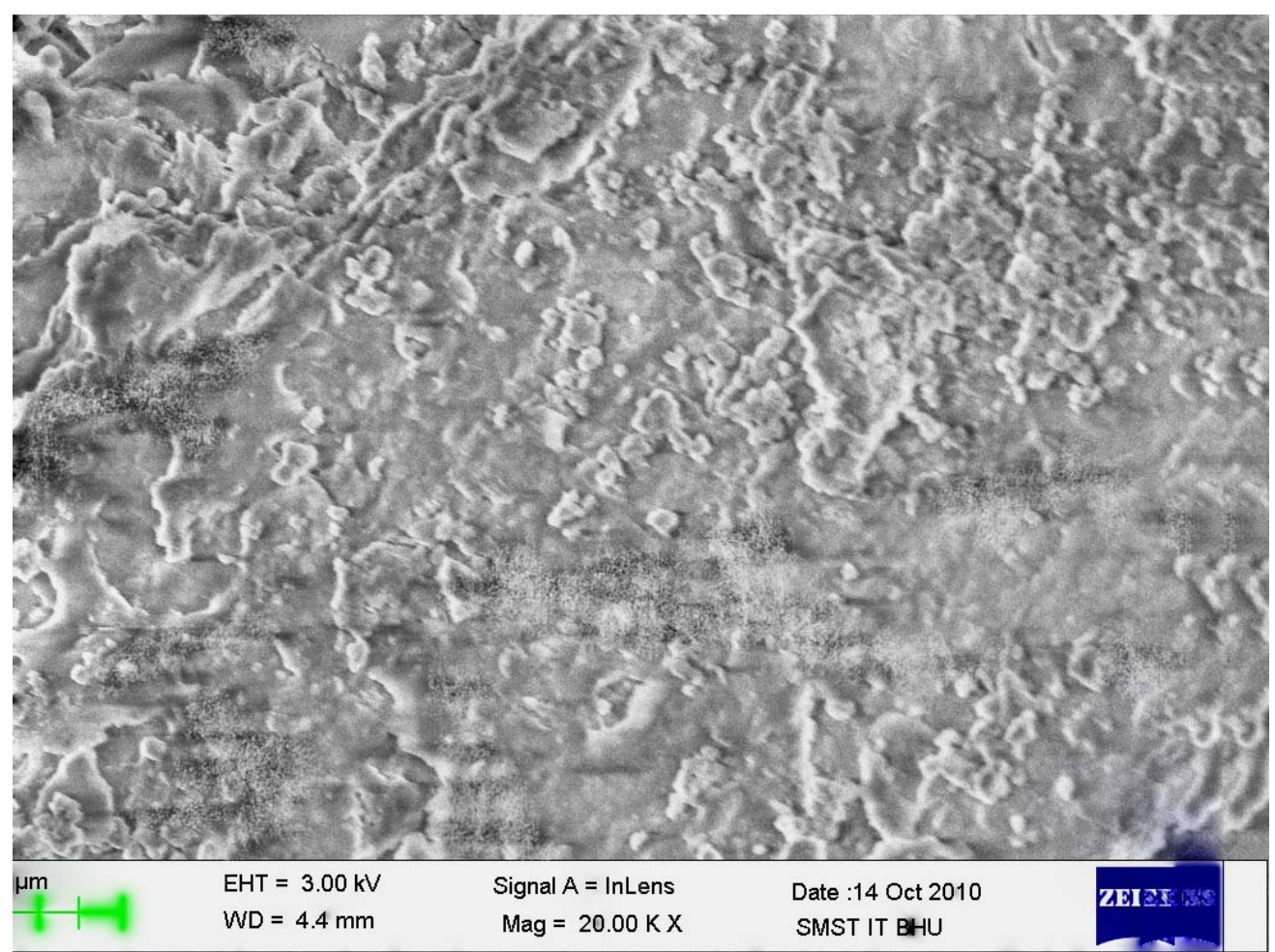

Figure 9. Scanning electron microscopy of grafted polymer II on silica at $20000 \times$ magnification.

UV irradiation and characterized by means of elemental analysis, FT-IR, $\mathrm{H}^{1} \mathrm{NMR}, \mathrm{C}^{13} \mathrm{NMR}$ spectral techniques. These polymers were grafted on silica surface to furnish polymer grafted silica particles. Silica particles were modified with APES to introduce amino groups on surface. Maleimide groups were attached to thus grafted amino ends on surface of silica particles and further Michael addition reactions were followed to graft copolymers on silica particles. Grafting steps were monitored and characterized using FTIR spectra. Several distinctive characteristics make the materials promising candidates for potential applications in material science. No catalyst is needed for the formation of the polymeric networks, so the materials are not contaminated with inorganic remains or byproduct as this is observed in other systems [29]. Zwitterionic nature provided by the sulfobetaine group endows them with biocompatibile nature for use in biomedical devices. Additionally, the fluorescence nature of these polyelectrolytes is interesting to explore their optoelectronic application.

\section{REFERENCES}

[1] M. Ozdemir, C. U. Yurteri and H.Sadikoglu, "Physical Polymer Surface Modification Methods and Applications in Food Packaging Polymers," Critical Reviews in Food Science and Nutrition, Vol. 39, No. 5, 1999, pp. 457-477. doi:10.1080/10408699991279240

[2] Z. Jia, S. Du and G. Tian, "Surface Modification of Acrylic
Fiber by Grafting of Casein," Journal of Macromolecular Science, Part A: Pure and Applied Chemistry, Vol. 44, No. 3, 2007, pp. 299-304. doi:10.1080/10601320601077351

[3] M. Suzuki, A. Kishida, H. Iwata and Y. Ikada, "Graft Copolymerization of Acrylamide onto a Polyethylene Surface Pretreated with Glow Discharge," Macromolecules, Vol. 19, No. 7, 1986, pp.1804-1808. doi:10.1021/ma00161a005

[4] M. Onishi, K. Shimura, Y. Seita, S. Yamashita, A. Takahashi and T. Masuoka, "Preparation and Properties of Plasma-Initiated Graft Copolymerized Membranes for Blood Plasma Separation," International Journal of Radiation Applications and Instrumentation. Part C. Radiation Physics and Chemistry, Vol. 39, No. 6, 1992, pp. 569-576. doi:10.1016/1359-0197(92)90114-U

[5] D. S. Wavhal and E. R. Fisher, "Hydrophilic Modification of Polyethersulfone Membranes by Low Temperature Plasma-Induced Graft Polymerization," Journal of Membrane Science, Vol. 209, No. 1, 2002, pp. 255-259. doi:10.1016/S0376-7388(02)00352-6

[6] Y. Q. Song, J. Sheng, M. Wei and X. B. Yuan, "Surface Modification of Polysulfone Membranes by Low-Temperature Plasma-Graft Poly(Ethylene Glycol) onto Polysulfone Membranes," Journal of Applied Polymer Science, Vol. 78, No. 5, 2000, pp. 979-985. doi:10.1002/1097-4628(20001031)78:5<979::AID-APP6 $0>3.0 . \mathrm{CO} ; 2-\mathrm{U}$

[7] J. Lei, X. Liao and D. Lin, "Studies on Surface Graft Copolymerization of Acrylic Acid onto LDPE Film through Corona Discharge," Chemical Journal on Inter- 
net, Vol. 2, 2000, Article ID: 021006pc.

[8] J. Lei, Q. Li, G. He and X. Lin, "Surface Graft Copolymerization of Acrylic Amide onto BOPP Film through Corona Discharge," Acta Chimica Sinica, Vol. 58, No. 5, 2000, pp. 598-600.

[9] J. Lei, M. Shi and J. Zhang, "Surface Graft Copolymerization of Hydrogen Silicon Fluid onto Fabric through Corona Discharge and Water Repellency of Grafted Fabric," European Polymer Journal, Vol. 36, No. 6, 2000, pp. 1277-1281. doi:10.1016/S0014-3057(99)00169-X

[10] S. Mok, D. J. Worsfold, A. Founda and T. Matsuura, "Surface Modification of Poly(Ether Sulfone) HollowFiber Membranes by $\gamma$-Ray Irradiation," Journal of Applied Polymer Science, Vol. 51, No. 1, 1994, pp. 193-199. doi:10.1002/app.1994.070510120

[11] A. F. Filho and A. S. Gomes, "Copolymerization of Styrene onto Polyethersulfone Films Induced by Gamma Ray Irradiation," Polymer Bulletin, Vol. 57, No. 4, 2006, pp. 415-421. doi:10.1007/s00289-006-0574-7

[12] E. Bucio, E. Arenas and G. Burillo, "Radiation Grafting of N-Isopropylacrylamide onto Polypropylene Films by Preirradiation Method," Molecular Crystals and Liquid Crystals, Vol. 447, No. 1, 2006, pp. 521-531. doi:10.1080/15421400500387593

[13] J. Deng, L. Wang, L. Liu and W. Yang, "Developments and New Applications of UV-Induced Surface Graft Polymerizations," Progress in Polymer Science, Vol. 34, No. 2, 2009, pp. 156-194. doi:10.1016/j.progpolymsci.2008.06.002

[14] G. Oster and O. Shibata, "Graft Copolymer of Polyacrylamide and Natural Rubber Produced by Means of Ultraviolet Light," Journal of Polymer Science, Vol. 26, No. 113, 1957, pp. 233-234. doi:10.1002/pol.1957.1202611311

[15] B. Kasemo and J. Gold, "Graft Copolymer of Polyacrylamide and Natural Rubber Produced by Means of Ultraviolet Light," Advances in Dental Research, Vol. 13, No. 1, 1999, pp. 8-20. doi:10.1177/08959374990130011901

[16] F. H. Jones, "Teeth and Bones: Applications of Surface Science to Dental Materials and Related Biomaterials," Surface Science Reports, Vol. 42, No. 3-6, 2001, pp. 75205. doi:10.1016/S0167-5729(00)00011-X

[17] D. Klee and H. Hocker, "Advances in Polymer Science: Biomedical Application/Polymer Blends," Biomedical Applications Polymer Blends, Vol. 149, 1999, pp. 1-55. doi:10.1007/3-540-48838-3 1

[18] B. D. Mather, K. Viswanathan, K. M. Miller and T. E. Long, "Michael Addition Reactions in Macromolecular Design for Emerging Technologies," Progress in Polymer Science, Vol. 31, No. 5, 2006, pp. 487-531. doi:10.1016/j.progpolymsci.2006.03.001

[19] M. J. Frisch, G. W. Trucks, H. B. Schlegel, G. E. Scuseria, M. A. Robb, J. R. Cheeseman, et al., "Gaussian 03, Revision D.01," Gaussian, Inc., Wallingford CT, 2004.
[20] W. Roberts and W. L. D. Liams, "Sultone Chemistry," Tetrahedron, Vol. 43, No. 6, 1987, pp. 1027-1062. doi:10.1016/S0040-4020(01)90041-9

[21] K. D. Schmitt, "Surfactant-Mediated Phase Transfer as an Alternative to Propanesultone Alkylation. Formation of a New Class of Zwitterionic Surfactants," Journal of Organic Chemistry, Vol. 60, No. 17, 1995, pp. 5474-5479. doi: $10.1021 / \mathrm{jo} 00122 \mathrm{a} 028$

[22] O. R. Gautun, P. H. J. Carlsen, T. Maldal, O. Vikane and E. Gilje, "Selective Synthesis of Aliphatic Ethylene Glycol Sulfonate Surfactants," Acta Chemica Scandinavica, Vol. 50, 1996, pp. 170-177. doi:10.3891/acta.chem.scand.50-0170

[23] J. H. Flanagan, S. H. Khan, S. Menchen, S. A. Soper and R. P. Hammer, "Functionalized Tricarbocyanine Dyes as Near-Infrared Fluorescent Probes for Biomolecules," Bioconjugate Chemistry, Vol. 8, No. 5, 1997, pp. 751-756. doi:10.1021/bc970113g

[24] G. Carrea, G. Ottolina, S. Riva, B. Danieli, G. Lesma and G. Palmisano, "Alkylation of Adenine, Adenosine, and $\mathrm{NAD}^{+}$with 1,3-Propanesultone. Synthesis of $N^{6}$-(3-Sulfonatopropyl)-NAD ${ }^{+}$, a New $\mathrm{NAD}^{+}$Derivative with Substantial Coenzyme Activity," Helvetica Chimica Acta, Vol. 71, No. 4, 1988, pp. 762-772. doi:10.1002/hlca.19880710411

[25] U. T. Ruegg and J. Rudinger, "Reaction of Cysteine Thiol Groups with 1,3-Propane Sultone: S-3-Sulphopropyl as a Modifying Group for Protein Chemistry," International Journal of Peptide and Protein Research, Vol. 6, No. 6, 1974, pp. 447-456. doi:10.1111/j.1399-3011.1974.tb02405.x

[26] Y. Ikenoue, Y. Saida, M. Kira, H. Tomozawa, H. Yahima and M. Kobayashi, "A Facile Preparation of a Self-Doped Conducting Polymer," Journal of the Chemical Society, Chemical Communications, Vol. 23, 1990, pp. 1694-1695. doi:10.1039/c39900001694

[27] S.-J. Xiao, S. Brunner and M. Wieland, "Reactions of Surface Amines with Heterobifunctional Cross-Linkers Bearing both Succinimidyl Ester and Maleimide for Grafting Biomolecules," Journal of Physical Chemistry B, Vol. 108, No. 42, 2004, pp. 16508-16517. doi:10.1021/jp047726s

[28] S. Riahi, F. Edris-Tabrizi, M. Javanbakht, M. R. Ganjali and P. Norouzi, "A Computational Approach to Studying Monomer Selectivity towards the Template in an Imprinted Polymer," Journal of Molecular Modeling, Vol. 15 , No. 7, 2004, pp. 829-836. doi:10.1007/s00894-008-0437-2

[29] C. Wood, B. Tan, A. Trewin, H. Niu, D. Bradshaw, M. J. Rosseinsky, Y. Z. Khimyak, N. L. Campbell, R. Kirk, E. Stockel and A. I. Cooper, "Hydrogen Storage in Microporous Hypercrosslinked Organic Polymer Networks," Chemistry of Materials, Vol. 19, No. 8, 2007, pp. 2034 2048. doi: $10.1021 / \mathrm{cm} 070356 \mathrm{a}$ 